\title{
06 DEVELOPMENT OF ASSESSMENT TOOLS ON SAFE SETTINGS FOR CHILD AND ADOLESCENT INJURY PREVENTION
}

doi:10.1136/injuryprev-2012-040580e.6

J Basilio*, L Orbillo. National Center for Disease Prevention and Control, Department of Health, Philippines

Background Injuries are among the leading causes of mortality and morbidity among children. Thus, the National Policy and Strategic Framework on Child Injury Prevention was developed and injury prevention was included as one of the essential interventions in the Philippine Child Survival Strategy. For a more focused approach, the settings-based interventions were adopted. These include places where children live, learn, play and work-the home, the school and the community.

Aims/Objectives/Purpose The Checklists serve as entry point to establish a safe home, safe school and safe community. It can also be used as an advocacy tool for implementation of the child injury strategic interventions.

Methods A meeting of various stakeholders was conducted for the conceptualisation and planning for child injury prevention, followed by a workshop to develop the safety assessment tools.

Results/Outcome The safe settings assessment tools for home, school and community were developed and field tested. Orientation on the use of the tools was conducted. Observations done in the three settings revealed various unsafe practices and structures which were presented to the local government for action.

Significance/Contribution to the Field The tool proved to be a good advocacy tool for action on safety measures in the community. Nationwide adoption of the tools is expected to bring down mortality and morbidity due to injuries. 